Article

\title{
Acute Exposure to Key Aquaculture Environmental Stressors Impaired the Aerobic Metabolism of Carassius auratus gibelio
}

\author{
Zongli Yao, Xiaoying Zhang, Qifang Lai *, Kai Zhou and Pengcheng Gao \\ Engineering Research Center for Saline-alkaline Water Fisheries, Sino-US Joint Laboratory of Aquatic Animal \\ Physiology, Key Laboratory of East China Sea Fishery Resources Exploitation, Ministry of Agriculture and Rural \\ Affairs, East China Sea Fisheries Research Institute, Chinese Academy of Fishery Sciences, Shanghai 200090, \\ China; yaozongli@hotmail.com (Z.Y.); zhangxy8123@163.com (X.Z.); zhoukai69@126.com (K.Z.); \\ legend04fsefan@163.com (P.G.) \\ * Correspondence: qifanglai@163.com
}

Received: 1 January 2020; Accepted: 7 February 2020; Published: 10 February 2020

check for updates

\begin{abstract}
Carassius auratus gibelio is an omnivore favored for its flavor and is commonly used as a benthic species in traditional pond polyculture. This study investigated the effects of common aquaculture stressors, such as high ammonia, high nitrite, high $\mathrm{pH}$, and hypoxia on the aerobic metabolism of $C$. auratus gibelio. The results showed that the standard metabolic rate (SMR) was positively correlated with ammonia, nitrite, and $\mathrm{pH}$, while the maximum metabolic rate (MMR) was negatively correlated with all four stressors. Thus, aerobic scope (AS) was reduced when C. auratus gibelio was exposed to high ammonia, high nitrite, high $\mathrm{pH}$, and hypoxia. The peak of post-prandial $\mathrm{O}_{2}$ consumption was positively correlated with nitrite, $\mathrm{pH}$, and the occurrence of the peak metabolic rate post-prandial was delayed in high ammonia, high nitrite, hypoxia, and high $\mathrm{pH}$ conditions. These findings indicated that, in experimental conditions, exposure to these environmental stressors can influence aerobic metabolism in C. auratus gibelio. With more energy required to maintain standard metabolic rates, less will be available for growth. While the $C$. auratus gibelio is one of the most hypoxia tolerance species, the reduction we observed in AS caused by stressors that commonly occur in ponds and in nature will likely affect growth in ponds and fitness in nature. These data have provided insight into the optimal, fitness-maximizing thresholds for these common stressors in this species of interest.
\end{abstract}

Keywords: aerobic metabolism; ammonia; nitrite; $\mathrm{pH}$; hypoxia; Carassius auratus gibelio

\section{Introduction}

When too high or too low, ammonia, nitrite, $\mathrm{pH}$, and oxygen can become stressors for aquatic animals in traditional pond aquaculture and natural water bodies. Physiological activities of fish are susceptible to physical and chemical environmental stressors, which can be reflected by changes in metabolic activity [1-4].

Ammonia is excreted by fish as a nitrogenous waste product. In feed-based aquaculture, only $20 \%$ to $40 \%$ of the nitrogen in the protein of feed used in aquaculture ponds is recovered in harvest biomass. The other $60 \%$ to $80 \%$ remains in the water as uneaten feed, or is deposited as feces or excreted as ammonia nitrogen by aquatic animals [5]. Ammonia exists as unionized ammonia $\left(\mathrm{NH}_{3}\right)$ and ionized ammonium $\left(\mathrm{NH}_{4}{ }^{+}\right)$in water. The toxicity of ammonia comes from the unionized form $\left(\mathrm{NH}_{3}\right)$, which can diffuse across gill membranes due to its lipid solubility and lack of charge. While fish can excrete ammonia as $\mathrm{NH}_{3}$ across gill membranes into water [6], high environmental ammonia 
reduces the outward flux of ammonia through the gills. As a result, blood and tissue ammonia levels can increase and fish can experience both the chronic and acute effects of ammonia toxicity [7].

Ammonia produced by fish can be eliminated by bacteria that convert it to nitrite and nitrate. Nitrite is one of the most common toxic nitrogenous compounds in aquaculture systems, it can accumulate during intensive aquaculture due to the excessive use of proteinaceous feed, higher stocking densities, and/or imbalances between bacterial nitrification and denitrification. Elevated concentrations of nitrite can be toxic to aquatic animals, acting by mechanisms that have been investigated in various freshwater species, showing that elevated concentrations of nitrite in pond water can affect growth, molting, immune response [8], and ammonia excretion $[9,10]$.

Dissolved oxygen (DO) is the primary limiting factor that dominates ectotherm physiology and behavior in aquatic ecosystems. DO regularly shows large fluctuations within the aquatic environment, especially in high density aquaculture. Hypoxia can result in reduced food consumption, slowed growth rates, reduced fecundity, or even death [11-13]. For these reasons, the impact of reduced environmental DO on the eco-physiology of fish must be studied and well understood.

Likewise, $\mathrm{pH}$ plays an important role in the maintenance of homeostasis in aquatic animals [14]. High $\mathrm{pH}$ water can cause immediate, dramatic inhibition of ammonia excretion and a subsequent increase in plasma ammonia $[4,14]$, which is potentially lethal. However, the physiological and behavioral responses of $C$. auratus gibelio to alkaline conditions have yet to be studied.

Measurements of the mass specific rate of $\mathrm{O}_{2}$ consumption $\left(\mathrm{MO}_{2}\right)$ have become common in research on fish biology and climate change, largely due to renewed interest and new developments that have related an aerobic scope (the range between minimum and maximum $\mathrm{MO}_{2}$, respectively) to whole-animal performance and fitness [15]. $\mathrm{MO}_{2}$ is influenced by various factors such as body mass, temperature, food intake, physiological state, activity level, and anabolism. The three fundamental metabolic variables are standard metabolic rate (SMR) [16], maximum metabolic rate (MMR), and aerobic metabolic scope (AS) [17]. SMR and MMR are usually calculated using measurements of oxygen consumption rate. The SMR is the minimum $\mathrm{MO}_{2}$, which allows for no activity, digestion, growth, or production of sexual products, as it represents the basic cost of being alive and is of major functional importance. If the $\mathrm{MO}_{2}$ is below the SMR, physiological function has been impaired in some way, and most species cannot survive for long in this state. The MMR, on the other end of the range, indicates the swimming speed and predation capability. Aerobic scope (AS), defined as the difference between the SMR and MMR, represents the oxygen usage capacity, which in turn indicates the total amount of aerobic energy available to the animal for processes including digestion, locomotion, growth, and reproduction.

C. auratus gibelio, is an omnivore that is popular because of its flavor, and is commonly used as a benthic species in Chinese pond polyculture [18]. It is a hypoxia-tolerant species but is relative sensitive to high nitrite and $\mathrm{pH}$ levels. To provide basic data for the physiology and metabolism of C. auratus gibelio, its aerobic metabolism in response to high ammonia, nitrite, $\mathrm{pH}$, and hypoxia were evaluated during acute exposure.

\section{Materials and Methods}

C. auratus gibelio were acclimatized for 2 weeks in $300 \mathrm{~L}$ tanks at $26.0 \pm 1{ }^{\circ} \mathrm{C}$ before experiments. During this period, the fish were fed daily using commercial pellets. Ammonia, nitrate, and $\mathrm{pH}$ levels were monitored and $1 / 3$ of the water was changed every day. Total ammonia was $0.13 \pm 0.02 \mathrm{mg} \mathrm{L}^{-1}$, nitrate was $0.17 \pm 0.02 \mathrm{mg} \mathrm{L}^{-1}$, and $\mathrm{pH}$ was $8.2 \pm 0.1$. Body mass and length of the fish (means $\pm \mathrm{SE}$ ) were $15.3 \pm 2.3 \mathrm{~g}$ and $9.0 \pm 0.6 \mathrm{~cm}$, respectively, and were not significantly different between treatment groups. All fish were collected under permits issued by local and national authorities, and experimental procedures were in accordance with national animal care regulations.

A custom-made respirometer was used for $\mathrm{MO}_{2}$ measurement. Prior to the experiment, fish underwent a fasting period of $48 \mathrm{~h}$, enough to ensure that they were in a post-absorptive state. In the intermittent flow through respirometry, water was continuously circulated through each respirometer using an in-line submersible pump within a recirculation loop. Each chamber $(2 \mathrm{~L})$ was equipped with 
a recirculation pump that only turned on when the inflow water was turned off for a measurement to ensure sufficient water mixing and minimize intermittent disturbance to the fish.

The study included numerous independent treatments: (1) In the control group, fish were exposed to fresh holding water; (2) experimentally manipulated fish were exposed to high-ammonia water $\left(0.5,1.0\right.$, and $\left.2.0 \mathrm{mg} \mathrm{L}^{-1}\right)$, high-nitrite water $\left(0.5,1.0\right.$, and $\left.1.5 \mathrm{mg} \mathrm{L}^{-1}\right)$, hypoxic water $\left(4.0\right.$ and $1.5 \mathrm{mg} \mathrm{L}^{-1}$, and $8.0 \mathrm{mg} \mathrm{L}^{-1}$ as a control), and high $\mathrm{pH}$ water (9.1,9.5, and 9.9). Ammonia was adjusted by adding ammonium chloride, nitrite was adjusted by adding sodium nitrite, DO was controlled by mixing nitrogen and oxygen, and alkaline (high $\mathrm{pH}$ ) water was prepared by adding sodium carbonate and sodium bicarbonate (total alkalinity was $30.0 \mathrm{~m} \mathrm{~mol} \mathrm{~L}^{-1}$ ).

\subsection{Measurements of Background Respiration}

Background respiration (to account for microbial respiration) was estimated by measuring the oxygen consumption rate in the respirometer without fish. Background respiration was measured before and after the experiment. Background oxygen consumption rates were used to correct fish $\mathrm{MO}_{2}$ values.

\subsection{Measurement of Standard Metabolic Rate (SMR)}

The duration of each treatment was $96 \mathrm{~h}$, SMR was measured every $24 \mathrm{~h}$. After an acclimation period $(24 \mathrm{~h})$, and oxygen consumption was measured every hour throughout a $96 \mathrm{~h}$ experimental period in each chamber (fish was put in the chamber singular). Dissolved oxygen (DO) was monitored every second using an oxygen meter (YSI 6600, measuring precision is $0.01 \mathrm{mg} \mathrm{L}^{-1}$ ), and the oxygen probe was calibrated before each experiment. The experiment was conducted in a dark environment. The fish appeared to be in excellent condition and remained quiet while measurements were made in the dark. Each group had three parallel replicates, with three fish in each.

\subsection{Measurement of Maximum Metabolic Rate (MMR)}

The duration of each treatment was $96 \mathrm{~h}$, MMR was measured every $24 \mathrm{~h}$. MMR was measured using an exhaustive chase protocol, where the experimenter manually chased the fish to exhaustion ( $5 \mathrm{~min}$ ). All individuals were visibly exhausted by the end of the $5 \mathrm{~min}$ exercise period as highlighted by a lack of response to an experimenter tapping the caudal fin. This was followed by a period of exposure to air (approximately $1 \mathrm{~min}$ ), with the goal of completely exhausting the fish. Measurements of $\mathrm{MO}_{2}$ began immediately after the fish was moved to a respirometer that was quickly sealed (within $20 \mathrm{~s}$ ). The duration of the measurement was $9 \mathrm{~min}$. Once MMR had been determined for each fish, the respirometers were set to the automated flush cycles outlined above and $\mathrm{MO}_{2}$ was measured for at least $6 \mathrm{~h}$ while the fish recovered. Each group had three parallel replicates, with three fish in each.

\subsection{Measurement of Post-Prandial $\mathrm{MO}_{2}$}

Post-prandial $\mathrm{MO}_{2}$ was measured after $96 \mathrm{~h}$ exposure of each treatments. Fish were fed $1 \%$ of their body weight daily, using the same feed as during holding. Any regurgitated pellets were counted and, in each case, were determined to be negligible relative to the size of the meal. Thirty minutes after feeding, the fish was replaced into their chamber and monitored for a further $24 \mathrm{~h} . \mathrm{MO}_{2}$ was measured every hour for the duration of the $96 \mathrm{~h}$ experimental period. Each group had three parallel replicates, with three fish in each. Peak post-prandial $\mathrm{MO}_{2}$ was determined for each fish that had continuous measurements as the highest hourly block value. Time-to-peak post-prandial $\mathrm{MO}_{2}$ was the number of hours post-prandial it took to reach the peak value.

\subsection{Statistical Analysis}

The lowest $10 \% \mathrm{MO}_{2}$ values were used to calculate SMR. The SMR $(\mathrm{mg} /(\mathrm{kg} \mathrm{h}))$ of each fish was calculated according to the following equation:

$$
S M R=\left(D O_{k}-D O_{k+1}\right) V /(t \times m)
$$


where $D O_{k}$ and $D O_{k+1}$ are the oxygen concentration $\left(\mathrm{mg} \mathrm{L}^{-1}\right)$ at point $\mathrm{k}$ and point $k+1$, respectively; $\mathrm{V}(\mathrm{L})$ is the total volume of the respirometer $(2 \mathrm{~L})$ minus the volume of the fish; $t(\mathrm{~h})$ is the interval $(5 / 60 \mathrm{~h})$ between points $k$ and $k+1 ; \mathrm{m}(\mathrm{kg})$ is the body mass of the fish.

MMR was measured after an exhaustive chase protocol, $\mathrm{MO}_{2}$ was measured for $9 \mathrm{~min}$, and MMR was taken as the steepest three min slope during this time. Subtracting SMR from MMR provided the AS value.

Within each acclimation group, a one-way ANOVA was performed. Results were considered statistically significant when $P<0.05$, and all results are presented as means $\pm \mathrm{SE}$. Statistically significant differences in SMR, MMR, AS, and peak post-prandial $\mathrm{MO}_{2}$, starting from the post-transfer $0 \mathrm{~h}$, among treatments at each time point were revealed using one-way ANOVAs, followed by multiple sample comparisons using the Holm-Sidak method. Nonlinear regression was used to analyze the correlation between concentration of treatments and SMR, MMR, or AS. Differences were considered significantly different when $P<0.05$. SAS9.3 (SAS Institute, Cary, NC, USA) was used for all statistical analyses. Line charts were created using SigmaPlot 11.0 (Systat Software, San Jose, CA, USA).

\section{Results}

\subsection{Effects of High Ammonia on Aerobic Metabolism}

SMR of $C$. auratus gibelio increased significantly with increasing ambient ammonia $(P<0.05)$. The relationship between SMR and ambient ammonia was quadratic (Figure 1a). In the $2.0 \mathrm{mg} \mathrm{L}^{-1}$ ammonia environment, SMR increased by $20.4 \%$ compared to the control. MMR decreased significantly with increasing ambient ammonia $(P<0.05)$. The relationship between MMR and ambient ammonia was exponential. In the $2.0 \mathrm{mg} \mathrm{L}^{-1}$ ammonia environment, the MMR decreased by $10.8 \%$ compared to the control (Figure 1a). AS decreased significantly with increasing ambient ammonia $(P<0.05)$. The relationship between AS and ambient ammonia was quadratic. In the $2.0 \mathrm{mg} \mathrm{L}^{-1}$ ammonia environment, AS decreased by $25.0 \%$ compared to the control (Figure 1a). The time to peak post-prandial $\mathrm{MO}_{2}$ was delayed with increasing ambient ammonia (Figure 2a).

\subsection{Effects of High Nitrite on Aerobic Metabolism}

SMR of $C$. auratus gibelio increased significantly with increasing ambient nitrite $(P<0.05)$. The relationship between SMR and ambient nitrite was quadratic. In the $1.5 \mathrm{mg} \mathrm{L}^{-1}$ nitrite environment, SMR increased by $35.3 \%$ compared to the control (Figure 1b). The MMR decreased significantly with increasing ambient nitrite $(P<0.05)$. The relationship between MMR and ambient nitrite was quadratic. In the $1.5 \mathrm{mg} \mathrm{L}^{-1}$ nitrite environment, the MMR decreased by $16.7 \%$ compared to the control (Figure $1 \mathrm{~b}$ ). AS decreased significantly with increasing ambient nitrite $(P<0.05)$. The relationship between AS and ambient nitrite was quadratic. In the $1.5 \mathrm{mg} \mathrm{L}^{-1}$ nitrite environment, AS decreased by $41.5 \%$ compared to the control (Figure $1 \mathrm{~b}$ ). Peak post-prandial $\mathrm{MO}_{2}$ increased with increasing ambient nitrite $(P<0.05)$, and time to peak post-prandial $\mathrm{MO}_{2}$ was delayed with increasing ambient nitrite (Figure $2 \mathrm{~b}$ ).

\subsection{Effects of Hypoxia on Aerobic Metabolism}

SMR of C. auratus gibelio increased significantly with increasing ambient dissolved oxygen $(P<0.05)$. The relationship between SMR and ambient dissolved oxygen was logarithmic. In the $1.5 \mathrm{mg} \mathrm{L}^{-1}$ dissolved oxygen environment (hypoxic), SMR decreased by 19.7\% compared to the control (Figure 1c). The MMR increased significantly with increasing ambient dissolved oxygen $(P<0.05)$. The relationship between MMR and ambient dissolved oxygen was logarithmic. In the $1.5 \mathrm{mg} \mathrm{L}^{-1}$ hypoxia treatment, the MMR decreased by $30.6 \%$ compared to the control (Figure 1c). AS decreased significantly with decreasing ambient dissolved oxygen $(P<0.05)$. The relationship between AS and ambient dissolved oxygen was logarithmic. In the $1.5 \mathrm{mg} \mathrm{L}^{-1}$ dissolved oxygen, AS decreased by $35.9 \%$ compared to the control (Figure 1c). Peak post-prandial $\mathrm{MO}_{2}$ increased with decreasing dissolved 
oxygen $(P<0.05)$, showing an inverse relationship. Time to peak post-prandial $\mathrm{MO}_{2}$ was delayed with decreasing dissolved oxygen (Figure 2c).

\subsection{Effects of High $\mathrm{pH}$ on Aerobic Metabolism}

SMR of $C$. auratus gibelio increased significantly with increasing ambient $\mathrm{pH}(P<0.05)$. The relationship between SMR and ambient $\mathrm{pH}$ was exponential. In the $9.9 \mathrm{pH}$ environment, SMR increased by $40.0 \%$ compared to the control (Figure 1d). The MMR decreased significantly with increasing ambient $\mathrm{pH}(P<0.05)$. The relationship between MMR and ambient $\mathrm{pH}$ was logarithmic. In the $9.9 \mathrm{pH}$ environment, the MMR decreased by $23.4 \%$ compared to the control (Figure 1d). AS decreased significantly with increasing ambient $\mathrm{pH}(P<0.05)$. The relationship between AS and ambient $\mathrm{pH}$ was quadratic. In the $9.9 \mathrm{pH}$ environment, AS decreased by $61.8 \%$ compared to the control (Figure 1d). The peak post-prandial $\mathrm{MO}_{2}$ increased with increasing $\mathrm{pH}(P<0.05)$ and had a quadratic relationship with $\mathrm{pH}$. The time to peak post-prandial $\mathrm{MO}_{2}$ was delayed with increasing $\mathrm{pH}$ (Figure $2 \mathrm{~d}$ ).

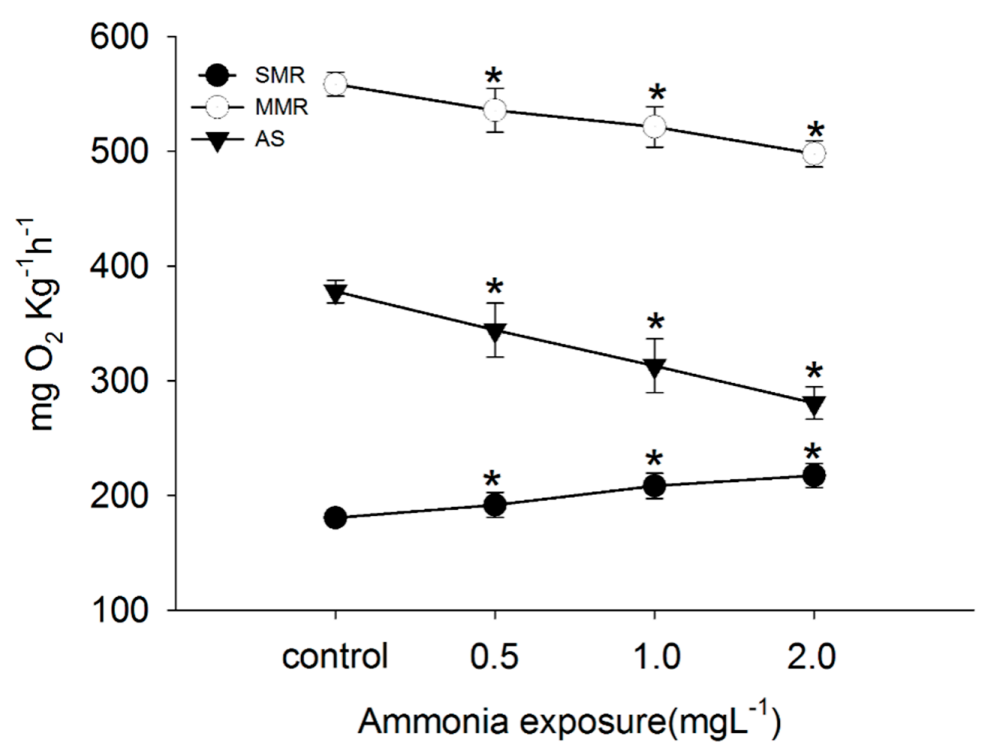

(a)

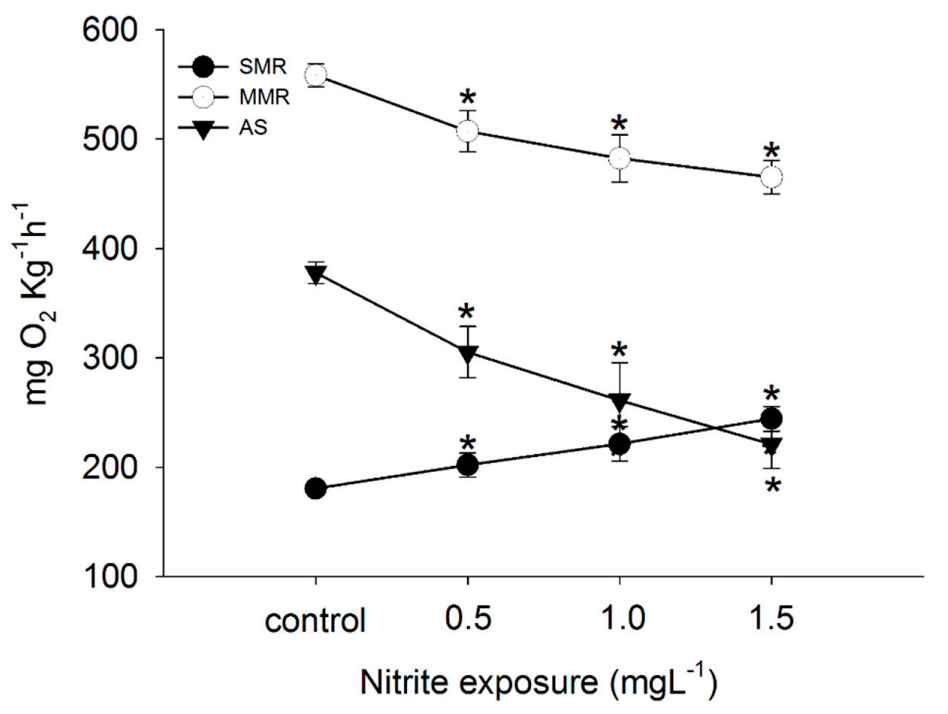

(b)

Figure 1. Cont. 


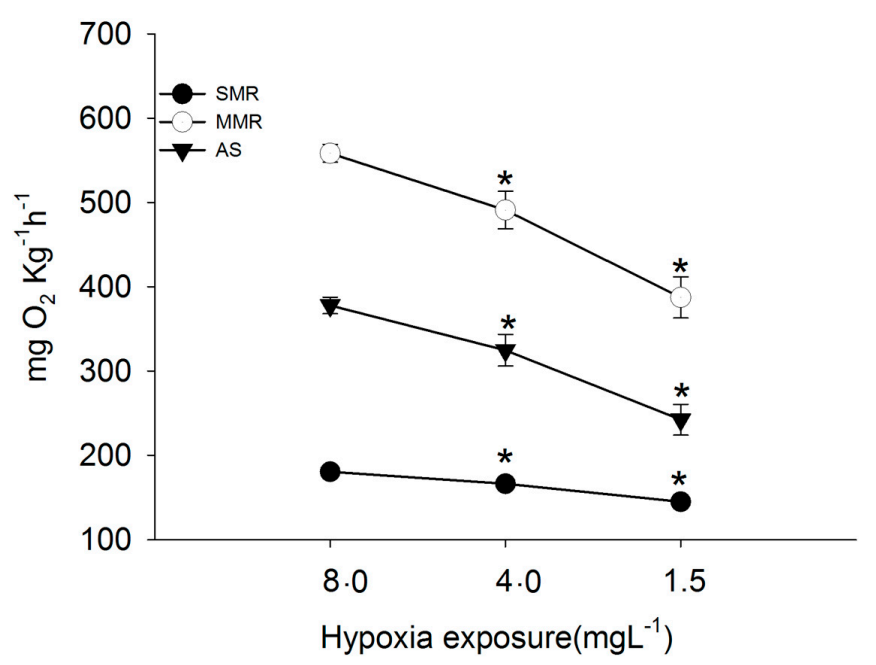

(c)

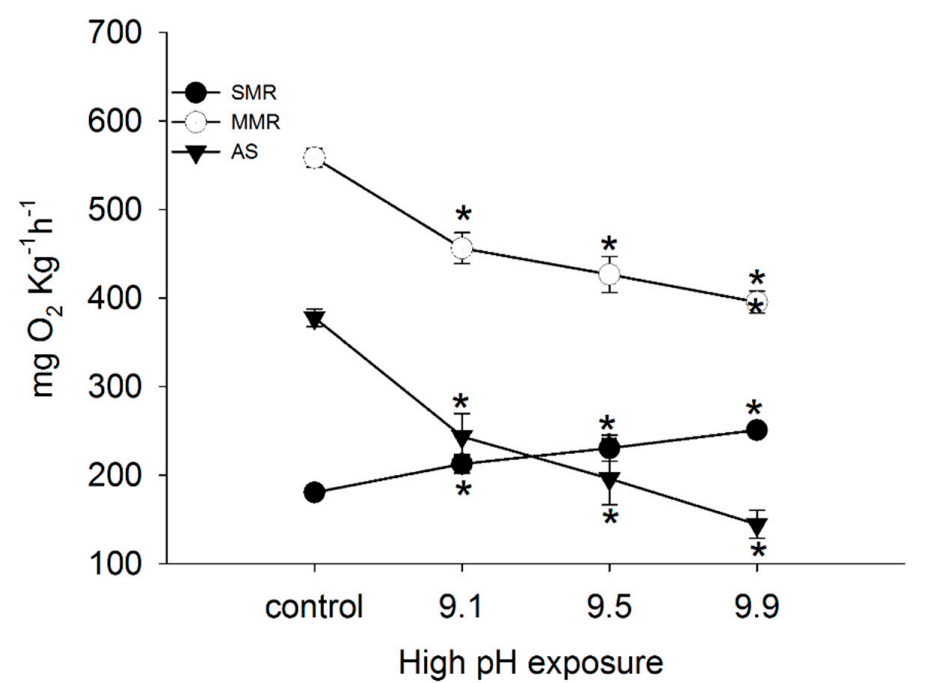

(d)

Figure 1. Standard metabolic rate (SMR), maximum metabolic rate (MMR), and aerobic scope (AS) of Carassius auratus gibelio exposed to high ammonia (control, $0.5 \mathrm{mg} \mathrm{L}^{-1}, 1.0 \mathrm{mg} \mathrm{L}^{-1}, 2.0 \mathrm{mg} \mathrm{L}^{-1}$ ) (a), high nitrite (control, $0.5 \mathrm{mg} \mathrm{L}^{-1}, 1.0 \mathrm{mg} \mathrm{L}^{-1}, 1.5 \mathrm{mg} \mathrm{L}^{-1}$ ) (b), hypoxia (control, $4.0 \mathrm{mg} \mathrm{L}^{-1}, 1.5 \mathrm{mg} \mathrm{L}^{-1}$ ) (c), and high $\mathrm{pH}$ (control, 9.1, 9.5, 9.9) (d). Values are means \pm SE. Statistically significant difference among treatments at each time point (“*”shows the significant different from control) were revealed by a one-way ANOVA test, followed by multiple comparisons with the Holm-Sidak method $(P \leq 0.05)$. 


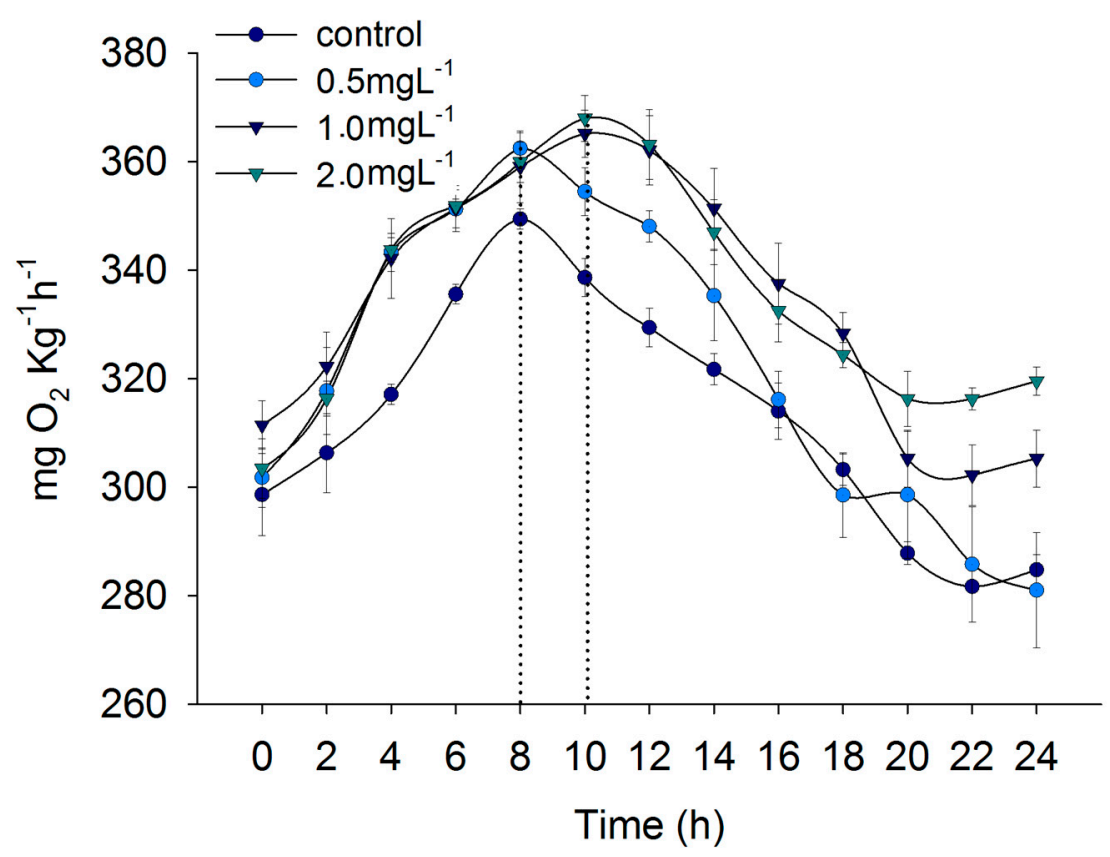

(a)

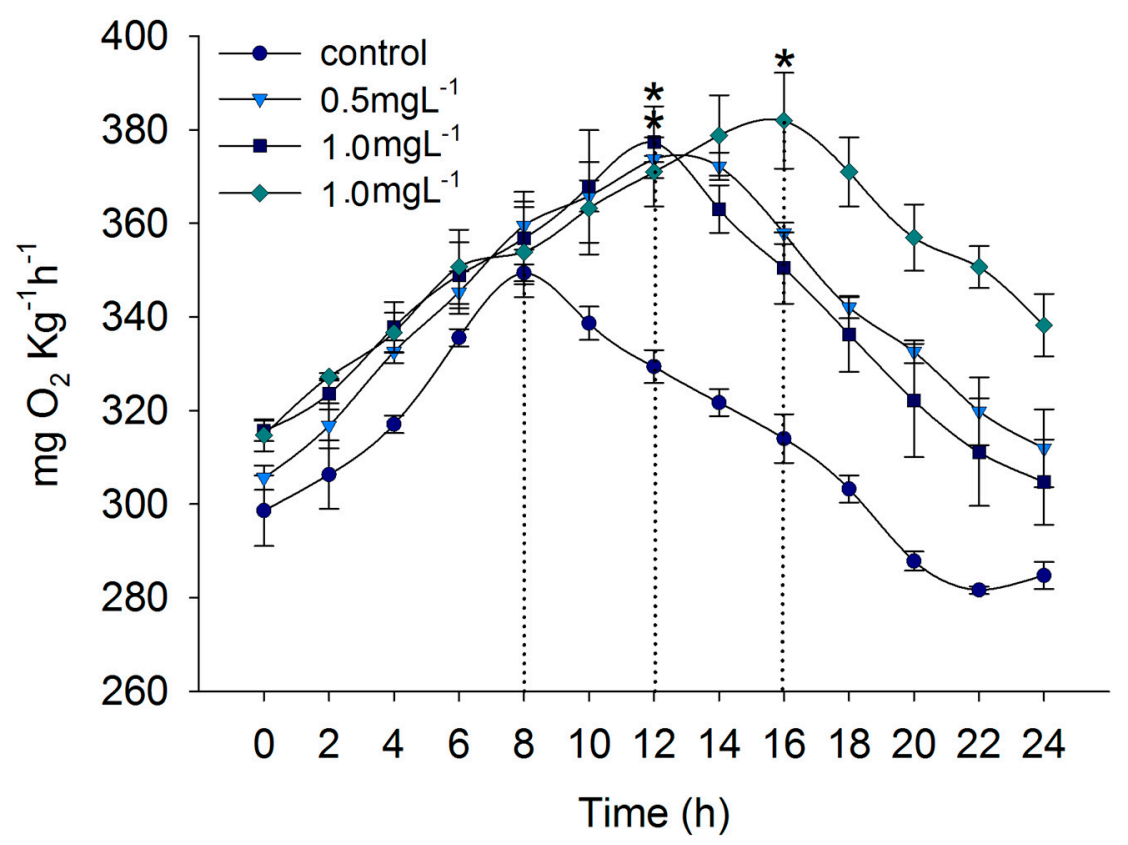

(b)

Figure 2. Cont. 


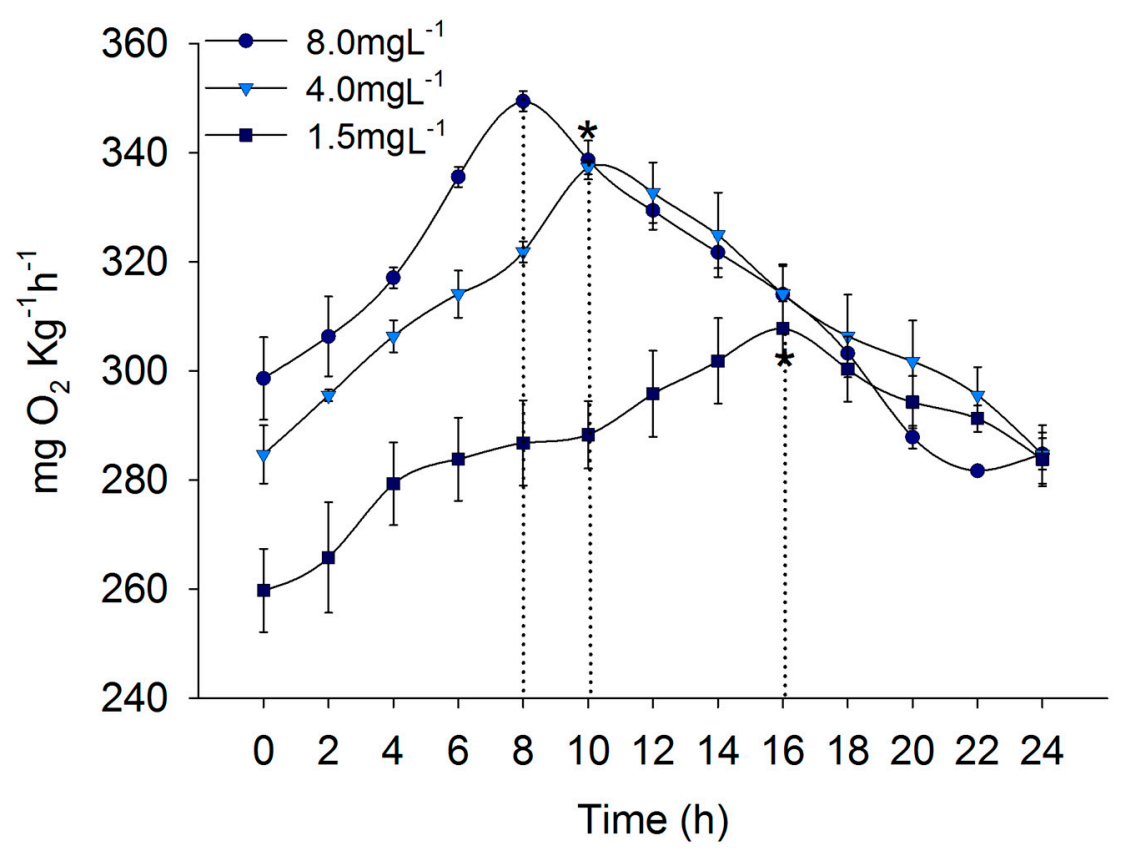

(c)

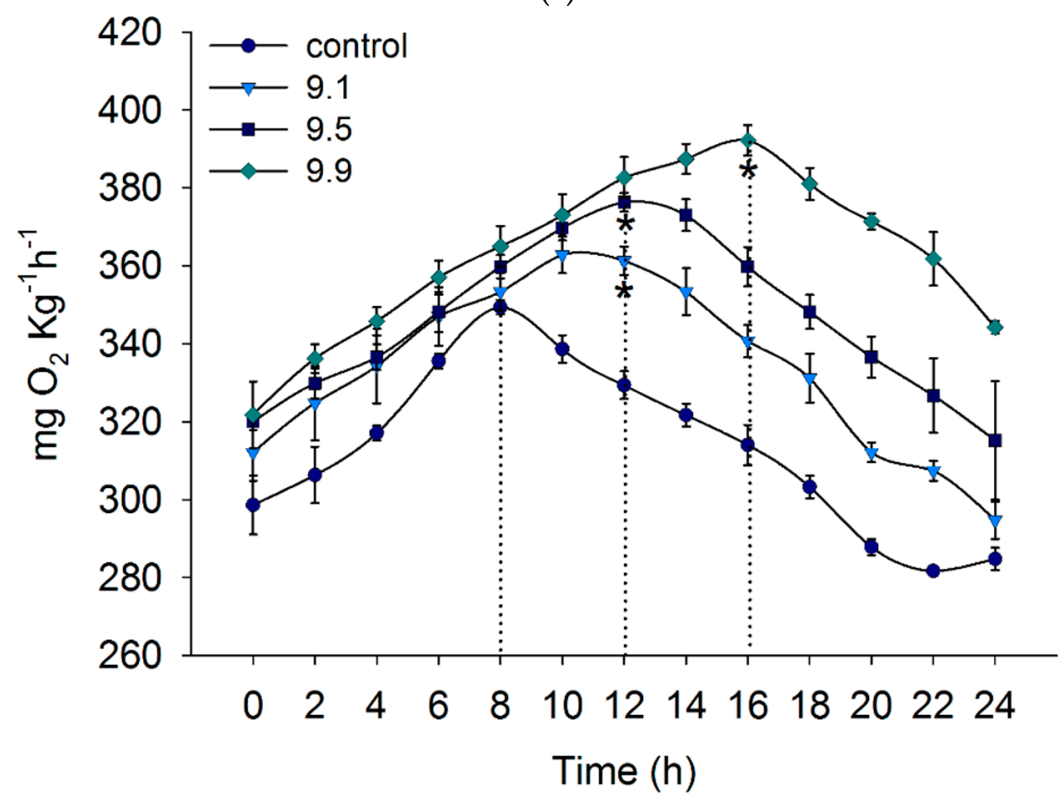

(d)

Figure 2. Post-prandial $\mathrm{MO}_{2}$ of Carassius auratus gibelio exposed to high ammonia (control, $0.5 \mathrm{mg}$ $\mathrm{L}^{-1}, 1.0 \mathrm{mg} \mathrm{L}^{-1}, 2.0 \mathrm{mg} \mathrm{L}^{-1}$ ) (a), high nitrite (control, $0.5 \mathrm{mg} \mathrm{L}^{-1}, 1.0 \mathrm{mg} \mathrm{L}^{-1}, 1.5 \mathrm{mg} \mathrm{L}^{-1}$ ) (b), hypoxia (control, $4.0 \mathrm{mg} \mathrm{L}^{-1}, 1.5 \mathrm{mg} \mathrm{L}^{-1}$ ) (c), and high $\mathrm{pH}$ (control, 9.1, 9.5, 9.9) (d).Values are means \pm SE. Statistically significant difference among treatments at each time point ("** shows the significant different from control) were revealed by a one-way ANOVA tests, followed by multiple comparisons with the Holm-Sidak method $(P \leq 0.05)$.

\section{Discussion}

While being one of the most hypoxia tolerance species, C. auratus gibelio's AS was reduced by key stressors such as high ammonia, high nitrite, hypoxia, and high $\mathrm{pH}$, that occur unpredictably in ponds and nature. A reduction in AS can lead to a reduction in growth in aquaculture ponds or reduced fitness in nature. The results described herein have provided novel insights into the optimal, fitness-maximizing thresholds of stressors for this economically valuable species. 


\subsection{Effects of High Ammonia on Aerobic Metabolism}

High ammonia impaired the aerobic metabolism of Carassius auratus gibelio. AS is used for locomotion and growth and was reduced as a function of the increase in SMR and decrease in MMR. A previous study suggested that the mechanism of ammonia poisoning in fish might be that ammonia interferers with amino acid transport, causing the swelling of astrocytes in the brain, disrupting the metabolism of amino acid neurotransmitters [19]. Fish attempt to excrete ammonia by energy-dependent transporters, such as V-type $\mathrm{H}^{+}$-ATPase [20] and $\mathrm{Na}^{+} / \mathrm{K}^{+}$-ATPase [21]. So, if the $C$. auratus gibelio needs more energy to excrete ammonia to defend against hyperammonemia, its supply of energy available to grow will be reduced. In addition, MMR and AS both decreased after exposure to ammonia, which may result in difficulty getting food and being more easily caught by predators. Although peak post-prandial $\mathrm{MO}_{2}$ was not different among treatments, delayed time-to-peak post-prandial $\mathrm{MO}_{2}$ indicated that $C$. auratus gibelio required more time for food ingestion. Due to the unforgiving nature of the wild, once this fish cannot meet its basic requirements, it may more easily become diseased.

\subsection{Effects of High Nitrite on Aerobic Metabolism}

High nitrite impaired the aerobic metabolism of C. auratus gibelio, which may translate to reduced locomotion and growth because of the increased SMR and decreased MMR, meanwhile, peak post-prandial $\mathrm{MO}_{2}$ and time-to-peak post-prandial $\mathrm{MO}_{2}$ both increased. The relative increase in peak post-prandial $\mathrm{MO}_{2}$ for $C$. auratus gibelio exposed to high nitrite reached a maximum of 2.1 times higher than SMR. Post-prandial $\mathrm{MO}_{2}$ represents the metabolic expenditures resulting from the nutritive process but may also include components relating to the energy requirement for ingestion, which varies among fish species and has been shown to be dependent upon several factors [22-24]. The increase of peak post-prandial $\mathrm{MO}_{2}$ and time-to-peak post-prandial $\mathrm{MO}_{2}$ were consistent with low feeding rate and food conversion efficiency [25]. When metabolism increases while the AS is narrower, the fish becomes more sensitive to hypoxia during digestion and may reduce ingestion. One physiological response to nitrite is an increase in methemoglobin. The hemoglobin becomes oxidized and unable to bind and carry molecules of oxygen [26]. In this case, the increased SMR in C. auratus gibelio was a result of either the induction of mitochondria dysfunction, or the increased energy demand by repair mechanisms and toxicant elimination [27]. The decreased MMR might be one side of a "trade-off" between the metabolic costs of chemical detoxification and fish activity.

\subsection{Effects of Hypoxia on Aerobic Metabolism}

Hypoxia impaired the aerobic metabolism of C. auratus gibelio, AS decreased because of the decrease in MMR, while peak post-prandial $\mathrm{MO}_{2}$ decreased and time-to-peak post-prandial $\mathrm{MO}_{2}$ increased in the hypoxic environment. SMR, MMR, and AS of C. auratus gibelio decreased when exposed to hypoxic conditions. We suggest, therefore, that $C$. auratus gibelio responses to environmental hypoxia were based mainly on suppressed metabolic rate. Fish of the genus Carassius evolved a specialized metabolic system that allows them to survive prolonged periods in hypoxia, even without oxygen by producing ethanol as their metabolic end-product [28]. Increased time-to-peak post-prandial $\mathrm{MO}_{2}$ indicate that although $C$. auratus gibelio survives in hypoxia by low metabolic rate, they need more time for digestion.

\subsection{Effects of High $p H$ on Aerobic Metabolism}

High $\mathrm{pH}$ impaired the aerobic metabolism of $\mathrm{C}$. auratus gibelio, AS decreased because of the increase in SMR and decrease in MMR, while peak post-prandial $\mathrm{MO}_{2}$ and time-to-peak post-prandial $\mathrm{MO}_{2}$ both increased. SMR decreased when exposed to high $\mathrm{pH}$, this was likely because high $\mathrm{pH}$ water affected ion equilibriums and ammonia excretion [29,30]. If excretion of ammonia was limited, the fish would need more energy to force excretion or utilize other energetically expensive ways to excrete 
ammonia, which would cut into the energy available for growth. Meanwhile, high $\mathrm{pH}$ and alkalinity could cause an acid base imbalance, such as respiratory alkalosis [4], thus demanding greater energy to cope with the disturbance. The relative increase in peak post-prandial $\mathrm{MO}_{2}$ for C. auratus gibelio exposed to high $\mathrm{pH}$ reached a maximum of 2.2 times higher than SMR, along with extremely narrow AS, which may result in difficulty getting food and a low ingestion rate. This is consistent with our findings about the growth performance of fish in alkaline water [31]. These findings give us some hint that extra oxygen should be provided when farming the fish in high $\mathrm{pH}$ water, especially during the feeding and ingestion period.

Author Contributions: Conception and design of research, Z.Y., Q.L. and X.Z.; performed experiments, Z.Y., X.Z., P.G., K.Z.; analyzed data, Z.Y. and X.Z.; interpreted results of experiments, Z.Y., Q.L. and X.Z.; prepared figures, Z.Y.; drafted manuscript, Z.Y. and X.Z.; edited and revised manuscript, Z.Y., X.Z., Q.L., K.Z. and P.G. All authors have read and agreed to the published version of the manuscript.

Funding: This research was funded by National key R\&D program of China (NO. 2018YFD0900603) and Special Scientific Research Funds for Central Non-profit Institutes (No.2016HY-ZD0601, No. 2019ZD0602).

Conflicts of Interest: The authors declare no conflict of interest.

\section{References}

1. Ren, Q.; Li, M.; Yuan, L.; Song, M.; Xing, X.; Shi, G.; Meng, F.; Wang, R. Acute ammonia toxicity in crucian carp Carassius auratus and effects of taurine on hyperammonemia. Comp. Biochem. Physiol. C Toxicol. Pharmacol. 2016, 190, 9-14. [CrossRef] [PubMed]

2. Moyson, S.; Liew, H.J.; Diricx, M.; Sinha, A.K.; Blust, R.; De Boeck, G. The combined effect of hypoxia and nutritional status on metabolic and ionoregulatory responses of common carp (Cyprinus carpio). Comp. Biochem. Physiol. A Mol. Integr. Physiol. 2015, 179, 133-143. [CrossRef] [PubMed]

3. Miao, L.H.; Lin, Y.; Pan, W.J.; Huang, X.; Ge, X.P.; Zhou, Q.L.; Liu, B.; Ren, M.C.; Zhang, W.X.; Liang, H.L.; et al. Comparative transcriptome analysis reveals the gene expression profiling in bighead carp (Aristichthys nobilis) in response to acute nitrite toxicity. Fish Shellfish Immunol. 2018, 79, 244-255. [CrossRef]

4. Yao, Z.; Guo, W.; Lai, Q.; Shi, J.; Zhou, K.; Qi, H.; Lin, T.; Li, Z.; Wang, H. Gymnocypris przewalskii decreases cytosolic carbonic anhydrase expression to compensate for respiratory alkalosis and osmoregulation in the saline-alkaline lake Qinghai. J. Comp. Physiol. B 2016, 186, 83-95. [CrossRef] [PubMed]

5. Zhou, L.; Boyd, C. Ammonia Nitrogen Management in Aquaculture Ponds. Aquaculture Magazine, October 2015.

6. Evans, D.H.; Cameron, J.N. Gill ammonia transport. J. Exp. Zool. 1986, 239, 17-23. [CrossRef]

7. Liew, H.J.; Sinha, A.K.; Nawata, C.M.; Blust, R.; Wood, C.M.; De Boeck, G. Differential responses in ammonia excretion, sodium fluxes and gill permeability explain different sensitivities to acute high environmental ammonia in three freshwater teleosts. Aquat. Toxicol. 2013, 126, 63-76. [CrossRef]

8. Gao, X.Q.; Fei, F.; Huo, H.H.; Huang, B.; Meng, X.S.; Zhang, T.; Liu, B.L. Impact of nitrite exposure on plasma biochemical parameters and immune-related responses in Takifugu rubripes. Aquat. Toxicol. 2020, 218, 105362. [CrossRef]

9. Alcaraz, G.; Espina, S. Effect of nitrite on the survival of grass carp, Ctenopharyngodon idella (Val.), with relation to chloride. Bull. Environ. Contam. Toxicol. 1994, 52, 74-79. [CrossRef]

10. Bath, R.N.; Eddy, F.B. Transport of nitrite across fish gills. J. Exp. Zool. 1980, 214, 119-121. [CrossRef]

11. Cottingham, A.; Huang, P.; Hipsey, M.R.; Hall, N.G.; Ashworth, E.; Williams, J.; Potter, I.C. Growth, condition, and maturity schedules of an estuarine fish species change in estuaries following increased hypoxia due to climate change. Ecol. Evol. 2018, 8, 7111-7130. [CrossRef] [PubMed]

12. Domenici, P.; Steffensen, J.F; Marras, S. The effect of hypoxia on fish schooling. Philos. Trans. R. Soc. Lond. B Biol. Sci. 2017, 372, 20160236. [CrossRef] [PubMed]

13. Mendez-Sanchez, J.F.; Burggren, W.W. Hypoxia-induced developmental plasticity of larval growth, gill and labyrinth organ morphometrics in two anabantoid fish: The facultative air-breather Siamese fighting fish (Betta splendens) and the obligate air-breather the blue gourami (Trichopodus trichopterus). J. Morphol. 2019, 280, 193-204. [CrossRef] 
14. Yao, Z.; Lai, Q.; Hao, Z.; Chen, L.; Lin, T.; Zhou, K.; Wang, H. Carbonic anhydrase 2-like and Na ${ }^{+}-\mathrm{K}^{+}$-ATPase alpha gene expression in medaka (Oryzias latipes) under carbonate alkalinity stress. Fish Physiol. Biochem. 2015, 41, 1491-1500. [CrossRef]

15. Clark, T.D.; Sandblom, E.; Jutfelt, F. Aerobic scope measurements of fishes in an era of climate change: Respirometry, relevance and recommendations. J. Exp. Biol. 2013, 216, 2771-2782. [CrossRef]

16. Chabot, D.; Steffensen, J.F.; Farrell, A.P. The determination of standard metabolic rate in fishes. J. Fish Biol. 2016, 88, 81-121. [CrossRef]

17. Peck, M.A.; Moyano, M. Measuring respiration rates in marine fish larvae: Challenges and advances. J. Fish Biol. 2016, 88, 173-205. [CrossRef]

18. Yun, B.; Yu, X.; Xue, M.; Liu, Y.; Wang, J.; Wu, X.; Han, F.; Liang, X. Effects of dietary protein levels on the long-term growth response and fitting growth models of gibel carp (Carassius auratus gibelio). Anim. Nutr. 2015, 1, 70-76. [CrossRef]

19. Ip, Y.K.; Chew, S.F. Ammonia production, excretion, toxicity, and defense in fish: A review. Front. Physiol. 2010, 1, 134. [CrossRef]

20. Nawata, C.M.; Hung, C.C.; Tsui, T.K.; Wilson, J.M.; Wright, P.A.; Wood, C.M. Ammonia excretion in rainbow trout (Oncorhynchus mykiss): Evidence for Rh glycoprotein and $\mathrm{H}^{+}$-ATPase involvement. Physiol. Genom. 2007, 31, 463-474. [CrossRef]

21. Chew, S.F.; Hiong, K.C.; Lam, S.P.; Ong, S.W.; Wee, W.L.; Wong, W.P.; Ip, Y.K. Functional roles of $\mathrm{Na}^{+} / \mathrm{K}^{+}$-ATPase in active ammonia excretion and seawater acclimation in the giant mudskipper, Periophthalmodon schlosseri. Front. Physiol. 2014, 5, 158. [CrossRef]

22. Bucking, C.; Fitzpatrick, J.L.; Nadella, S.R.; Wood, C.M. Post-prandial metabolic alkalosis in the seawater-acclimated trout: The alkaline tide comes in. J. Exp. Biol. 2009, 212, 2159-2166. [CrossRef]

23. Clark, T.D.; Brandt, W.T.; Nogueira, J.; Rodriguez, L.E.; Price, M.; Farwell, C.J.; Block, B.A. Postprandial metabolism of Pacific bluefin tuna (Thunnus orientalis). J. Exp. Biol. 2010, 213, 2379-2385. [CrossRef]

24. Nie, L.J.; Fu, S.J. Metabolic, behavioral, and locomotive effects of feeding in five cyprinids with different habitat preferences. Fish Physiol. Biochem. 2017, 43, 1531-1542. [CrossRef]

25. Sun, H.; Li, J.; Tang, L.; Yang, Z. Responses of crucian carp Carassius auratus to long-term exposure to nitrite and low dissolved oxygen levels. Biochem. Syst. Ecol. 2012, 44, 224-232. [CrossRef]

26. Tilak, K.S.; Veeraiah, K.; Raju, J.M. Effects of ammonia, nitrite and nitrate on hemoglobin content and oxygen consumption of freshwater fish, Cyprinus carpio (Linnaeus). J. Environ. Biol. 2007, 28, 45-47.

27. Lin, Y.; Miao, L.H.; Pan, W.J.; Huang, X.; Dengu, J.M.; Zhang, W.X.; Ge, X.P.; Liu, B.; Ren, M.C.; Zhou, Q.L.; et al. Effect of nitrite exposure on the antioxidant enzymes and glutathione system in the liver of bighead carp, Aristichthys nobilis. Fish Shellfish Immunol. 2018, 76, 126-132. [CrossRef]

28. Fagernes, C.E.; Stenslokken, K.O.; Rohr, A.K.; Berenbrink, M.; Ellefsen, S.; Nilsson, G.E. Extreme anoxia tolerance in crucian carp and goldfish through neofunctionalization of duplicated genes creating a new ethanol-producing pyruvate decarboxylase pathway. Sci. Rep. 2017, 7, 7884. [CrossRef]

29. Wilkie, M.P.; Wood, C.M. Nitrogenous Waste Excretion, Acid-Base Regulation, and lonoregulation in Rainbow Trout (Oncorhynchus mykiss) Exposed to Extremely Alkaline Water. Physiol. Zool. 1991, 64, 1069-1086. [CrossRef]

30. Yao, Z.; Yi, X.; Lai, Q.; Zhou, K.; Gao, P. Fish nitrogen excretion in saline-alkaline water: A review. Mar. Fish. 2018, 40, 740-751.

31. Yao, Z.L.; Lai, Q.F.; Zhou, K.; Rizalita, R.E.; Wang, H. Developmental biology of medaka fish (Oryzias latipes) exposed to alkalinity stress. J. Appl. Ichthyol. 2010, 26, 397-402. [CrossRef]

(C) 2020 by the authors. Licensee MDPI, Basel, Switzerland. This article is an open access article distributed under the terms and conditions of the Creative Commons Attribution (CC BY) license (http://creativecommons.org/licenses/by/4.0/). 